\title{
The Effect of Angle and Velocity on Change of Direction Biomechanics: An Angle-Velocity Trade-Off
}

\author{
Thomas Dos'Santos $^{1} \cdot$ Christopher Thomas $^{1,2} \cdot$ Paul Comfort $^{1} \cdot$ Paul A. Jones ${ }^{1}$
}

Published online: 9 August 2018

(c) The Author(s) 2018

\begin{abstract}
Changes of direction (CODs) are key manoeuvres linked to decisive moments in sport and are also key actions associated with lower limb injuries. During sport athletes perform a diverse range of CODs, from various approach velocities and angles, thus the ability to change direction safely and quickly is of great interest. To our knowledge, a comprehensive review examining the influence of angle and velocity on change of direction (COD) biomechanics does not exist. Findings of previous research indicate the biomechanical demands of CODs are 'angle' and 'velocity' dependent and are both critical factors that affect the technical execution of directional changes, deceleration and reacceleration requirements, knee joint loading, and lower limb muscle activity. Thus, these two factors regulate the progression and regression in COD intensity. Specifically, faster and sharper CODs elevate the relative risk of injury due to the greater associative knee joint loading; however, faster and sharper directional changes are key manoeuvres for successful performance in multidirectional sport, which subsequently creates a 'performance-injury conflict' for practitioners and athletes. This conflict, however, may be mediated by an athlete's physical capacity (i.e. ability to rapidly produce force and neuromuscular control). Furthermore, an 'angle-velocity tradeoff' exists during CODs, whereby faster approaches compromise the execution of the intended COD; this is influenced by an athlete's physical capacity. Therefore, practitioners and researchers should acknowledge and understand the implications of angle and velocity on COD biomechanics when: (1) interpreting biomechanical research; (2) coaching COD technique; (3) designing and prescribing COD training and injury reduction programs; (4) conditioning athletes to tolerate the physical demands of directional changes; (5) screening COD technique; and (6) progressing and regressing COD intensity, specifically when working with novice or previously injured athletes rehabilitating from an injury.
\end{abstract}

Thomas Dos'Santos

t.dossantos@edu.salford.ac.uk

1 Human Performance Laboratory, Directorate of Sport, Exercise, and Physiotherapy, University of Salford, Greater Manchester, UK

2 School of Health, Sport and Professional Practice, University of South Wales, Pontypridd, Wales, UK 


\section{Key Points}

Change of direction angle and approach velocity are critical factors that impact the directional change technical execution, deceleration and reacceleration requirements, knee joint loading, and lower limb muscle activity. Thus, these two factors regulate the progression and regression in change of direction intensity.

An 'angle-velocity trade-off' exists during change of direction, whereby faster approaches compromise the execution of the intended directional change.

Change of direction biomechanical demands are 'angle' and 'velocity' dependent; therefore, practitioners and researchers should understand the implications of these two factors when coaching and screening change of direction technique, creating and implementing strength and conditioning programs, and interpreting change of direction research.

\section{Introduction}

The ability to change direction efficiently is central to the success of multidirectional sports [1-6]; however, changing direction has also been identified as a primary action resulting in non-contact anterior cruciate ligament (ACL) injury [7-14]. Athletes perform a diverse range of change of direction (COD) angles, at a variety of approach velocities in sport [1, 5, 15-18]. A plethora of biomechanical investigations has investigated a spectrum of angled direction changes $\left(30^{\circ}-180^{\circ}\right)$, at various approach velocities $\left(\sim 3-7 \mathrm{~m} \cdot \mathrm{s}^{-1}\right)$, in an attempt to provide insight into the biomechanical risk factors associated with increased injury risk and the mechanics required for faster performance (Tables 1, 2, 3, 4). However, it worth noting that COD angle and approach velocity are critical factors influencing COD biomechanics, and include knee joint loading, whole body kinetics and kinematics, ground reaction force (GRF) characteristics, muscle activation, velocity of centre of mass, deceleration and propulsive requirements, technical, and task execution of the COD (Tables 1, 4). This should be acknowledged when interpreting the biomechanical literature.

The biomechanical demands of changes of directions (CODs) are described as 'angle dependent' and 'velocity dependent', whereby the technical execution and whole body kinetics and kinematics are likely to differ between different angled CODs [19-30], and also influenced by the approach velocity [31-35]. Thus, the purpose of this review was to examine the effect of angle and velocity of CODs on various biomechanical parameters including GRF properties, joint kinetics and kinematics, performance (time), injury risk factors (knee abduction moments, knee abduction angle), task execution (executed angle of COD), and muscle activation. A further aim was to discuss the implications of these factors on coaching COD technique, strength and conditioning training prescription, screening COD technique, and progression/regression of COD intensity when prescribing COD training. In addition, this review discusses the concept of an 'angle-velocity trade-off' when changing direction. Understanding the mechanics associated with faster performance and injury risk reduction are of great interest to practitioners, thus highlighting the importance of this review. For the purpose of this review, a sidestep involves a lateral foot-plant opposite to the direction of travel. Conversely, a crossover cut involves using the plant foot corresponding towards the same direction of travel. Finally, a pivot is a bilateral turning strategy where one foot rotates and remains in contact with the ground (typically for directional changes $\geq 135^{\circ}$ ).

\section{Effect of Angle on COD Biomechanics}

Numerous directional changes of various angles are performed in sport [1, 15-17] and, as such, have been extensively examined to gain an understanding of the associated injury risk factors [27, 32, 36-39] and kinematic and kinetic determinants of faster performance [30, 40-42]. Forty-fivedegree sidesteps have been thoroughly examined across the literature $[22,25-27,31,39,41,43-48]$, with directional changes of $30^{\circ}[28,49-51], 60^{\circ}[34,50,52,53], 67^{\circ}$ [32], $75^{\circ}$ [40], $90^{\circ}[22,25,26,36,38,54,55], 110^{\circ}[27,48$, $56], 135^{\circ}[22,35]$ and $180^{\circ}[22,29,36,37,47,57-60]$ also being investigated. However, the biomechanical demands of CODs are angle dependent (Table 1), as the angle of COD influences the magnitude of knee joint loading [22, 27-30], affects the deceleration and reacceleration requirements of the COD [23-26, 30], influences the magnitude of braking and propulsive forces [19, 22, 25, 27, 29], and impacts the orientation of the force vector to perform the COD [25]. Moreover, the angle of the COD results in different techniques $[26,30]$ and joint and segmental differences in order to execute the directional change [26], while also influencing lower limb muscle activity and estimated energy expenditure [23].

\subsection{Ground Reaction Force Characteristics and Whole-Body Centre of Mass Velocity are Angle Dependent}

Researchers have shown that the COD angle influences the braking and propulsive force characteristics of the final foot contact (FFC) (plant phase) [19, 22, 25, 27, 29] and also the braking force characteristics of the penultimate foot contact 


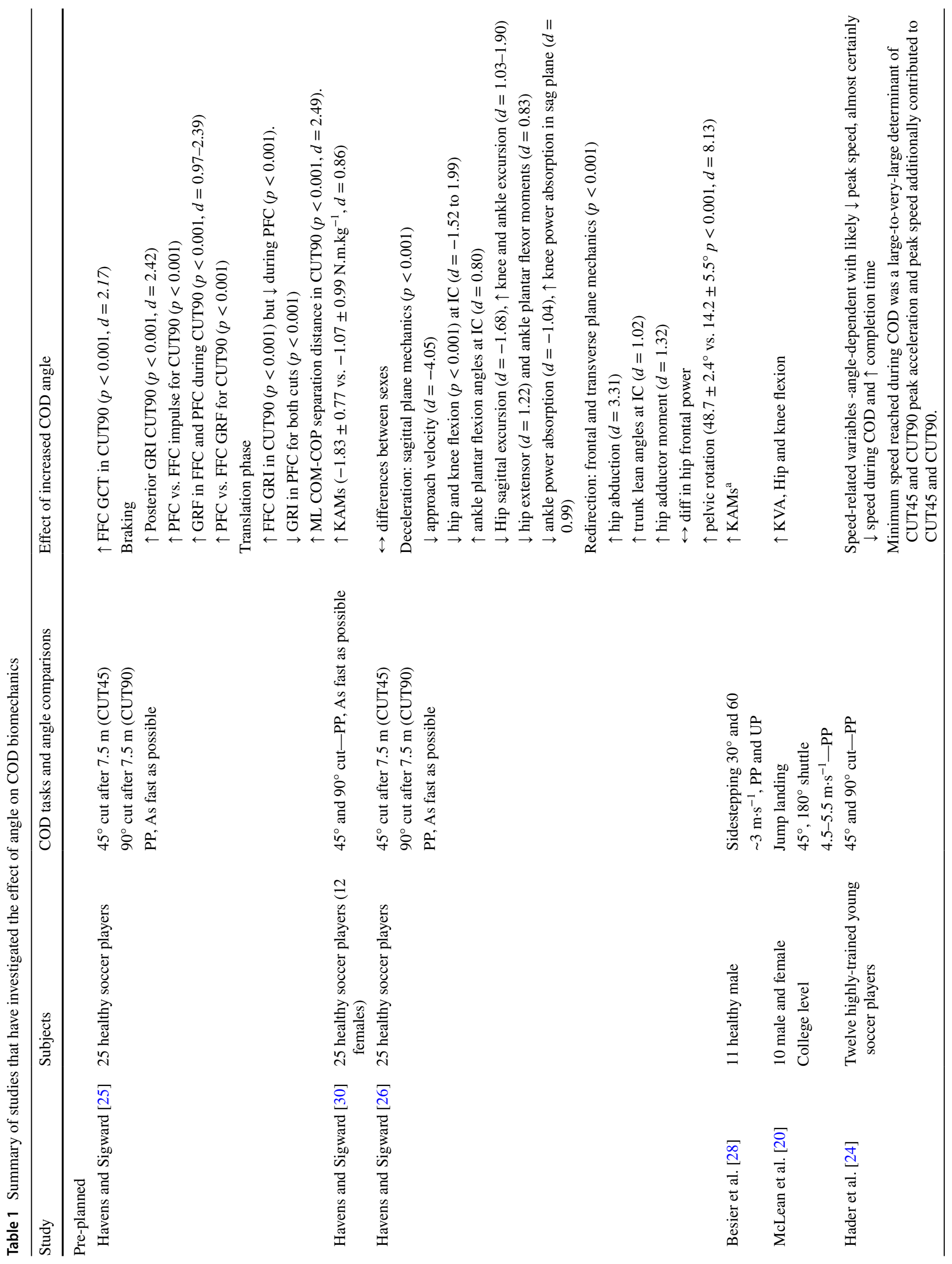




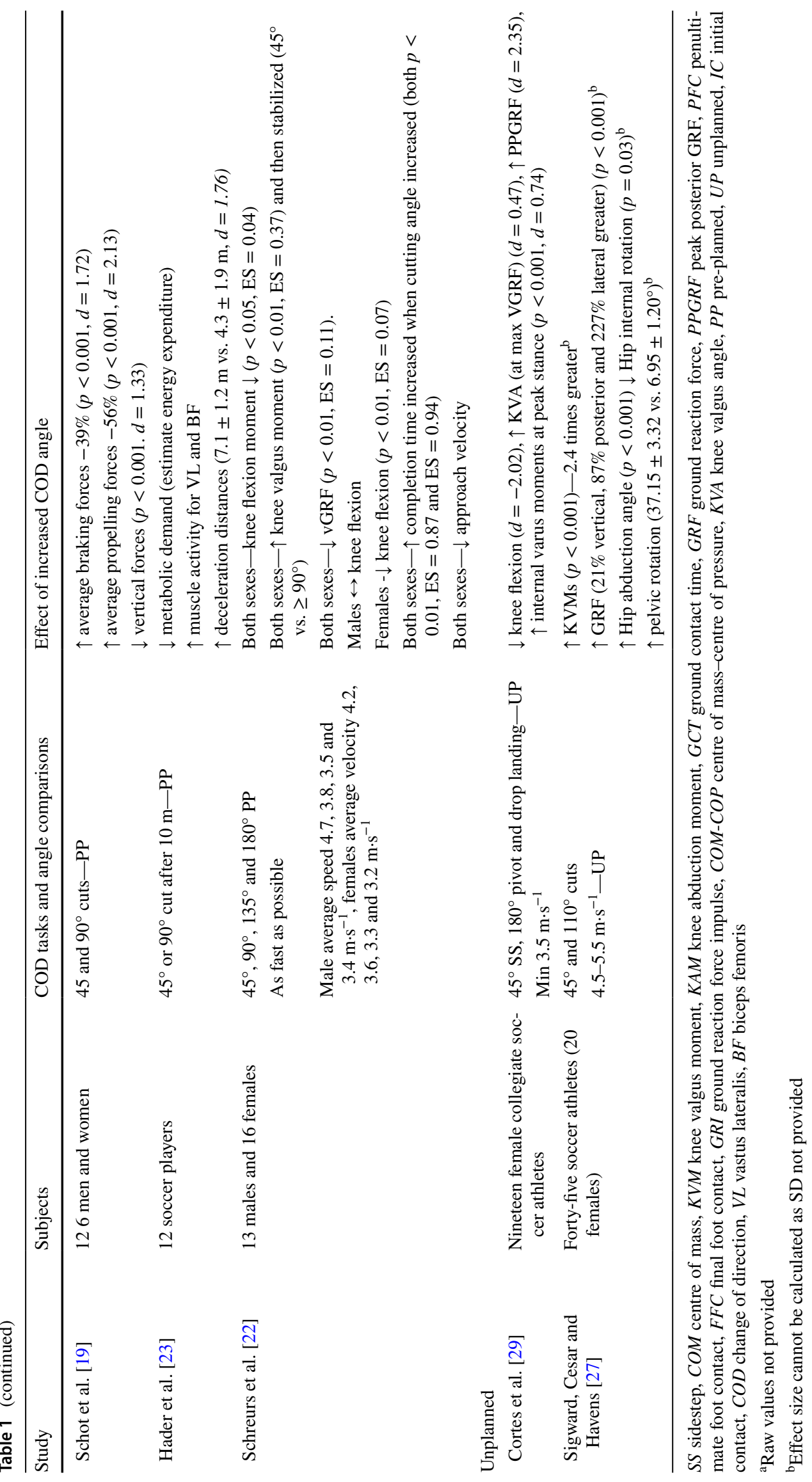


(PFC) (step prior to plant phase) [25] (Table 1). Schot et al. [19] reported significantly greater average braking forces and propulsion forces during a $90^{\circ}$ cut compared to a $45^{\circ}$ cut. Likewise, vertical, posterior and lateral GRFs were $21 \%$, $87 \%$ and $228 \%$ greater, respectively, during a $110^{\circ}$ cut in comparison to a $45^{\circ}$ cut in both male and female soccer players [27]. These results not only confirm that the GRF magnitudes are significantly greater with sharper cuts, but the direction requirements of the force are different (i.e. greater posterior and laterally directed force for sharper CODs). Conversely, Schreurs et al. [22] documented significantly $(p<0.01)$ greater vertical GRF in $45^{\circ}$ cuts in comparison to sharper CODs $\left(90^{\circ}, 135^{\circ}\right.$ and $\left.180^{\circ}\right)$. However, GRF is a three-component vector, but a downfall of the work by Schreurs et al. [22] is only the vertical component of GRF was examined.

To our knowledge, only one study has directly compared the GRF characteristics of the PFC between different angled CODs [25], observing greater posterior braking GRFs and ground contact times (GCTs), thus ground reaction impulse (GRI) during the $90^{\circ}$ cut in both PFC and FFC compared to $45^{\circ}$ cutting. Interestingly, posterior GRF and impulse were greater in the PFC compared to the FFC during the $90^{\circ}$ cut; however, this result was not the case for the $45^{\circ}$ cut, whereby the braking forces were more evenly distributed across both foot contacts. These findings support Andrews et al. [61] description of cutting as a multi-step action and highlight the importance of the braking forces during the PFC for sharper cuts. Researchers have reported that greater braking force characteristics over the PFC were associated with lower knee joint loads in the cutting or turning limb during $90^{\circ}$ cuts and $180^{\circ}$ turns [36]. Faster $180^{\circ}$ performance has also been associated with greater PFC horizontal braking forces [58-60], while substantial braking forces have also been reported in the PFC during $60^{\circ}$ [34] and $135^{\circ}$ [35] CODs. Collectively, the braking force characteristics of CODs are 'angle dependent', with a limited role of the PFC when changing direction $\leq 45^{\circ}$, but a prominent role for CODs $\geq 60^{\circ}$ during pre-planned tasks (Fig. 1). Unfortunately, however, the results of Jones et al. [62] indicate that unanticipated situations do not allow postural adjustments prior to the FFC to evoke greater braking force characteristics during the PFC; however, it should be noted that the unanticipated COD task involved responding to a light stimuli, which is more challenging than using a sports-specific stimulus [63, 64], and it also lacks specificity to the sporting situations where athletes typically scan and process kinematic and postural cues prior to changing direction [65]. Further research is warranted investigating the role of the PFC during unanticipated tasks utilising sports-specific stimuli.

Havens and Sigward [25] also examined the kinetic profile over the translation phase (shift from sagittal to frontal plane) and reported greater medio-lateral (ML) GRFs and longer GCTs and, thus, greater ML GRI demonstrated during the $90^{\circ}$ cut. Normative GCTs are presented in Table 2 for different angled directional changes indicating a longer GCT with increased angle. The longer GCTs could be attributed to sharper CODs requiring longer braking force application, therefore braking impulse (impulse $=$ force $\times$ time, thus change in momentum), in order to reduce the velocity (i.e. change in momentum) and redirect the athlete into the new intended direction $[25,26]$. Interestingly, the greater ML GRI observed by Havens and Sigward [25] was accompanied with greater ML centre of mass-centre of pressure (COM-COP) distances, suggesting athletes modify their COM-COP distances via greater lateral foot-plant distances and trunk lean into the intended direction to generate ML force and impulse (Table 1). This observation is supported by previous research reporting a strong relationship $(r=$ 0.59 ) between lateral foot-plant distance and peak medial GRF during $90^{\circ}$ cutting [38]. Consequently, these results suggest individuals modify their stance time and GRFs, thus impulse (during deceleration and reacceleration phases), and modify their COM-COP differently, and, accordingly, to the angle of the COD.

\subsection{Whole-Body Centre of Mass Velocity and Deceleration Requirements are Angle Dependent}

The angle of COD can also impact the velocity profile when changing direction (i.e. approach velocity and exit velocity), whereby sharper CODs result in reduced approach velocities and exit velocities [22, 24-26] (Table 1 and Fig. 1). Havens and Sigward [25] reported lower velocities at initial contact (IC) of the PFC and FFC during a $90^{\circ}$ cut compared to a $45^{\circ}$ cut. Similarly, Hader et al. [24] also observed lower approach velocities and lower velocities during the COD when comparing $90^{\circ}$ and $45^{\circ}$ cuts. Furthermore, Hader et al. [23] also reported longer deceleration distances for $90^{\circ}$ cuts compared to $45^{\circ}$ cuts (Table 1 ). These results support previous studies that have highlighted the importance of preliminary deceleration prior to sharper CODs [35, 61, 66]. The lower approach velocities observed during sharper CODs [22, 24-26] are most likely explained by greater braking forces in the PFC and FFC to reduce the velocity (i.e. change in momentum) and execute the intended COD. Therefore, COD angle will largely determine the velocity that can be maintained and govern the subsequent deceleration requirements of the directional change [23-26] (Fig. 1).

\subsection{Effect of COD Angle on Joint Kinetics and Kinematics}

When changing direction, the technique chosen is also angle dependent (Table 1); however, a limited number of 


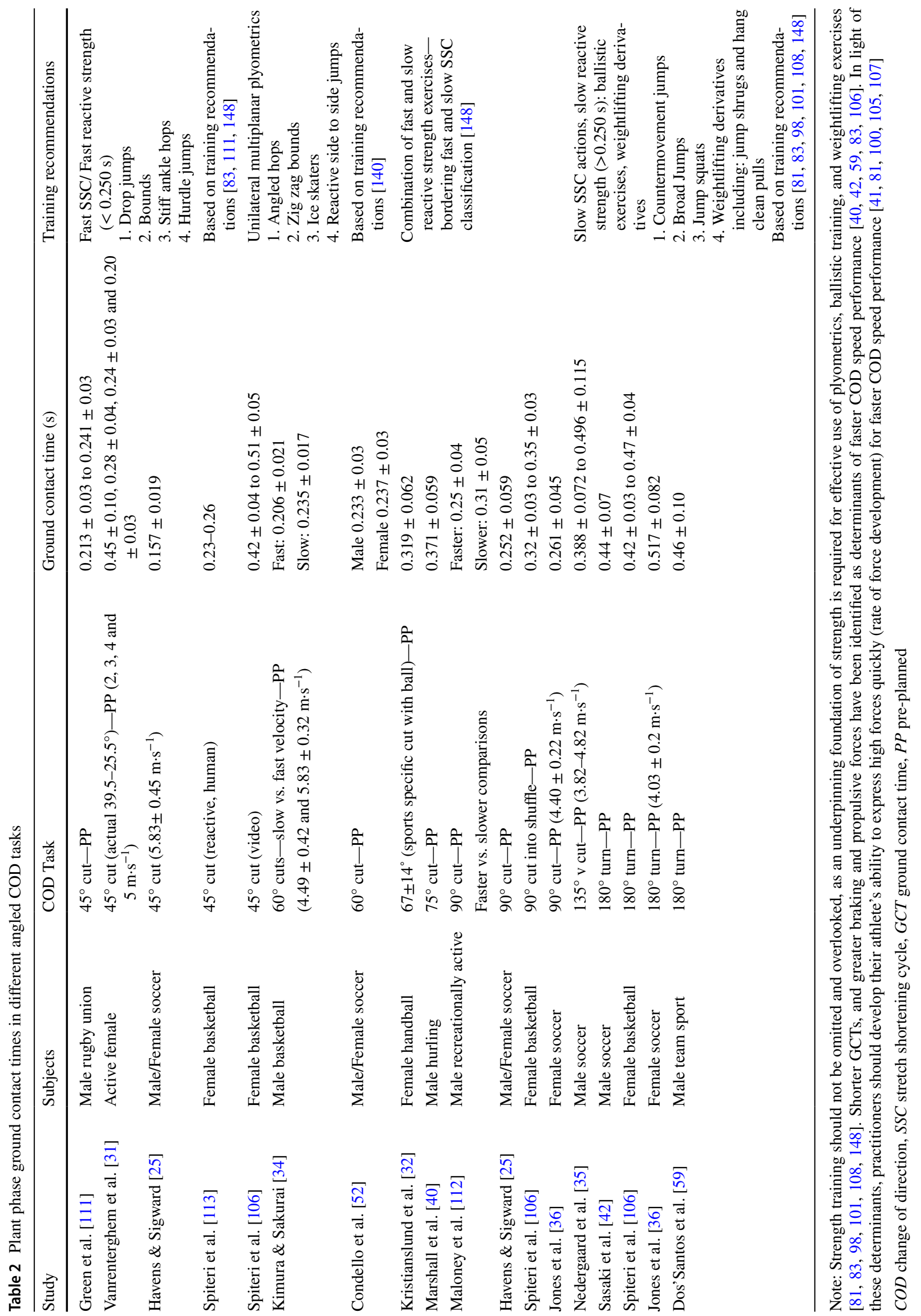


Table 3 Summary of studies that have examined executed cutting angle

\begin{tabular}{|c|c|c|c|c|}
\hline Study & Velocity $\left(\mathrm{m} \cdot \mathrm{s}^{-1}\right)$ & $\begin{array}{l}\text { COD task-intended angle } \\
\text { of COD task }\end{array}$ & $\begin{array}{l}\text { Method of determining } \\
\text { cutting angle }\end{array}$ & Actual angle of COD \\
\hline Besier et al. [28] & $\sim 3$ & $60^{\circ}$ cut $(\mathrm{SS})$ - $\mathrm{PP}$ & $\begin{array}{l}=\tan ^{-1}\left[\left(y_{i}-y_{i-1}\right) /\left[\left(x_{i}-\right.\right.\right. \\
\left.\left.x_{i-1}\right)\right], \text { where } i=i \text { th time } \\
\text { point } \\
X \text { and } y \text { displacements of } \\
\text { the pelvic center (ante- } \\
\text { rior/posterior and medio/ } \\
\text { lateral disablements) }\end{array}$ & $56.4^{\circ} \pm 4.4^{\circ}$ \\
\hline Vanrenterghem et al. [31] & $2.0,3.0,4.0$ and 5.0 & $45^{\circ}$ cut $(\mathrm{SS})$ - $\mathrm{PP}$ & Angle of $\mathrm{COM}$ & $\begin{array}{l}34.91^{\circ}, 29.41^{\circ}, 23.81^{\circ} \text { and } \\
17.51^{\circ} \text {-with increased } \\
\text { approach velocities }\end{array}$ \\
\hline Condello et al. [52] & As fast as possible & $\begin{array}{l}60^{\circ} \text { cut (SS) (inside angle } \\
\left.120^{\circ}\right) \text { - PP }\end{array}$ & $\begin{array}{l}\text { Computed from two-line } \\
\text { vectors connecting } \\
\text { pelvis centre (midpoint of } \\
\text { ASIS) positions projected } \\
\text { to the floor (x-y-plane) } \\
\text { Line } 1=1.5 \mathrm{~m} \text { before } \\
\text { initial plate contact and } \\
\text { initial plate contact. Line } \\
2=\text { Plate push-off and } \\
1.5 \mathrm{~m} \text { after plate push-off }\end{array}$ & $\sim 150^{\circ}$ inside angle \\
\hline Suzuki et al. [55] & $\begin{array}{l}\text { As fast as possible } \\
3.82 \pm 0.28 \text { and } 3.67 \pm \\
0.31^{\mathrm{a}}\end{array}$ & $90^{\circ} \mathrm{SS}$ and $\mathrm{XOC}-\mathrm{PP}$ & $\begin{array}{l}\text { Angle between horizontal } \\
\text { velocity vectors of the } \\
\text { whole-body COM at foot } \\
\text { strike and toe-off }\end{array}$ & $\begin{array}{l}\mathrm{SS}=40.5^{\circ} \pm 8.7^{\circ} \\
\mathrm{XOC}=33.0^{\circ} \pm 6.8^{\circ}\end{array}$ \\
\hline David et al. [116] & As fast as possible & $90^{\circ}$ cut $(\mathrm{SS})-\mathrm{PP}$ & $\begin{array}{l}\text { COM position at touch } \\
\text { down and toe off }\end{array}$ & $75.6^{\circ}$ \\
\hline Rovan et al. [66] & $\begin{array}{l}2.77 \\
4.16\end{array}$ & $\begin{array}{l}\text { Jog: } 30^{\circ}, 60^{\circ}, 90^{\circ}, 120^{\circ} \text {, } \\
150^{\circ} \text { and } 180^{\circ} \\
\text { Running: } 30^{\circ}, 60^{\circ}, 90^{\circ}, \\
120^{\circ}, 150^{\circ} \text { and } 180^{\circ}-\mathrm{PP}\end{array}$ & $\begin{array}{l}\text { Difference in direction of } \\
\text { COM movement between } \\
\text { steps (based on GNSS } \\
\text { and data) }\end{array}$ & $\begin{array}{l}\text { Jog: } 7.5^{\circ}, 10.7^{\circ}, 15.0^{\circ}, 16.2^{\circ} \text {, } \\
\quad 9.6^{\circ}, 1.5^{\circ} \\
\text { Running: } 6.9^{\circ}, 12.7^{\circ}, 14.6^{\circ}, \\
7.0^{\circ}, 8.3^{\circ}, 3.2^{\circ}\end{array}$ \\
\hline
\end{tabular}

$C O D$ change of direction, $S S$ sidestep, XOC crossover cut, COM centre of mass, ASIS anterior superior iliac spine, GNSS global navigation satellite system, $P P$ pre-planned

${ }^{\text {a}}$ Velocity at foot strike

studies have compared whole-body kinematics and kinetics between different angled CODs [26]. Havens and Sigward [26] reported joint and segmental differences during the deceleration and reacceleration phases of $45^{\circ}$ and $90^{\circ}$ cuts (Table 1). Notably, the authors' results demonstrated that the deceleration demands of a $90^{\circ}$ cut may not be evenly distributed across all joints, with a greater reliance on the knee. This finding is concerning because greater peak knee extensor moments, peak posterior GRF and increased quadriceps activity can increase anterior tibial shear force [67], thus ACL loading [68-72]. However, biomechanical deficits in the sagittal plane alone cannot rupture the ACL [73], but a combination of loading in several planes is required [74-77].

Interestingly, during the redirection phase greater hip abduction, greater trunk lean angles at IC and greater hip adductor moments were observed during the $90^{\circ}$ cut [26]. Greater hip abduction has been reported to be a biomechanical risk factor associated with knee abduction moments (KAM-synonymous with knee valgus moments for the purpose of this review) [39], thus ACL injury risk [78], and is also a commonly observed visual characteristic of noncontact ACL injuries $[9,79]$. This abducted lower extremity position is often discouraged in ACL injury prevention programmes [44], but increased hip abduction is necessary to create a larger ML COM-COP (to create a lateral foot plant) distance $[26,27]$ and subsequent lateral propulsion for executing sharper CODs $[25,38,80]$. This may create a 'performance-injury conflict' from a technique perspective, whereby a greater hip abducted position is necessary to create greater ML COM-COP distances and generate ML forces, but concurrently elevates injury risk due to the potential to generate larger KAMs, because the force vector acts more laterally relative to the knee joint centre [30, 38, 39]. However, this conflict in technique is mediated by an athlete's physical capacity (i.e. ability to rapidly produce force and neuromuscular control) $[58,81-84]$ such that stronger athletes with optimal mechanics (i.e. sufficient trunk control, no knee valgus) $[32,37,38,44,45]$ are able to tolerate 


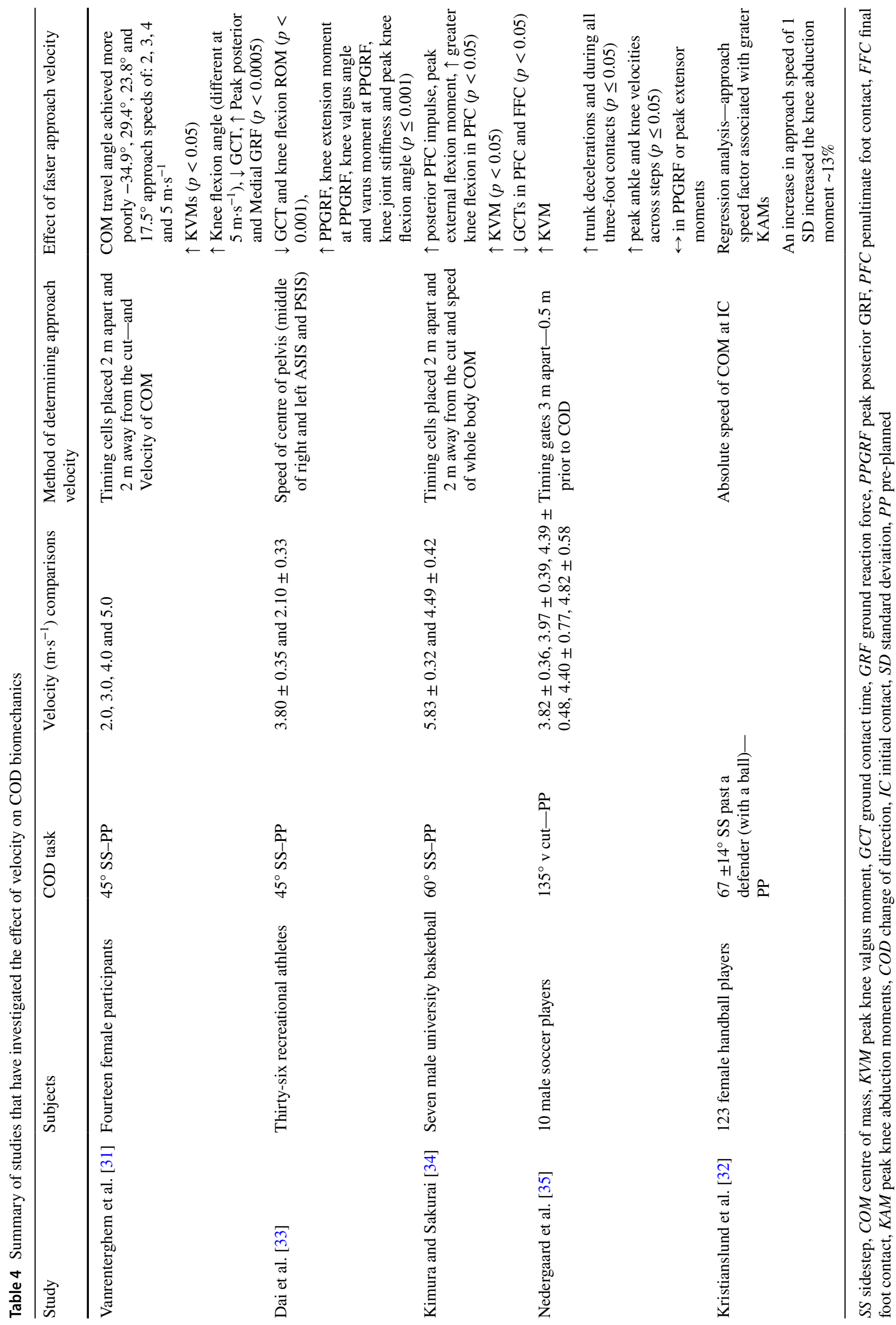



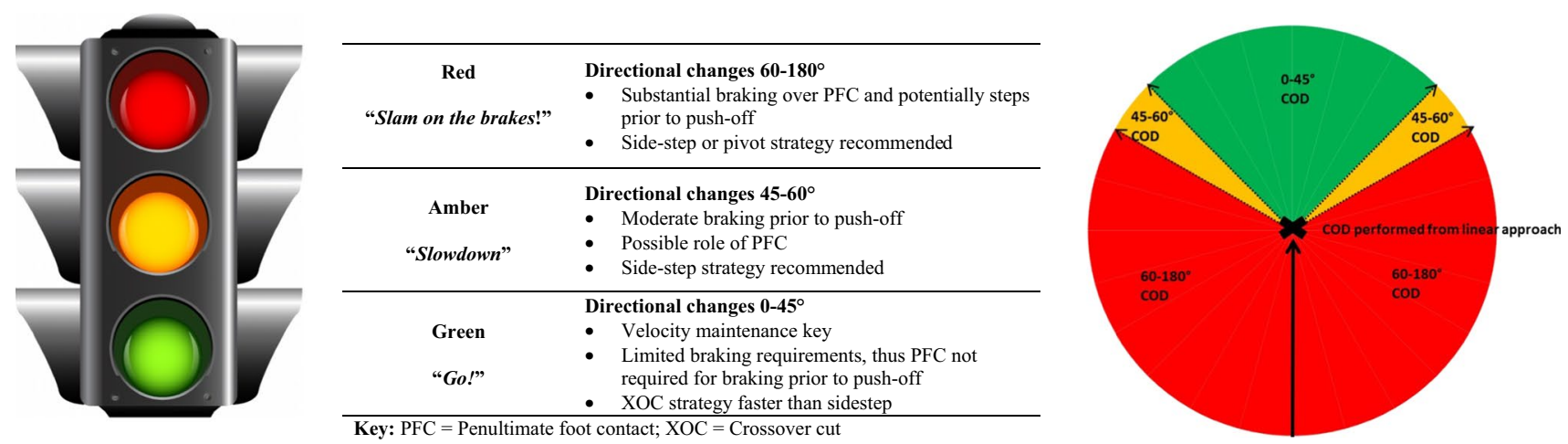

Fig. 1 Traffic light system indicating braking strategy and technique requirements for different angled directional changes based on a linear approach. Based on the results of previous research [23-25, 34-38, 55, 58-61, 66]

the higher loads experienced and could, thus, adopt such techniques.

Havens and Sigward [26] also found hip function to differ between tasks (Table 1). For example, the hip may act as a stabiliser during the $90^{\circ}$ cut due to the greater hip adductor moments and relatively low hip frontal and transverse power generation. Conversely, the hip may contribute to propulsion during $45^{\circ}$ cuts due to greater hip sagittal and transverse power generation, and transition from hip adductor to hip abductor moments during the stance. Notably, greater pelvic rotation was demonstrated during the $90^{\circ}$ cut, approximately $35^{\circ}$ more into the new intended direction compared to the $45^{\circ}[26]$, similar to research that compared $110^{\circ}$ cuts to $45^{\circ}$ cuts [27]. These findings suggest that athletes may achieve the greater redirection requirements by rotating their whole body and not just solely the lower limb. From a performance perspective, it may be worthwhile to coach techniques that emphasise whole body rotation and trunk lean towards the intended direction during sharper angled cuts [26, 27, 40], because Marshall et al. [40] reported greater lateral turn (thorax) towards the intended direction was strongly associated with faster $75^{\circ} \mathrm{COD}$ performance $(r=0.51, p<0.01)$. However, decelerating in the rotated position would result in force absorption and loading in the transverse and frontal planes, in contrast to absorbing and decelerating the force through the sagittal plane, which may be a safer technique $[37,73]$.

\subsection{Sharper CODs Increase the Relative Lower Body Loading}

Although the mechanisms of ACL injury are multifactorial [85], COD lower limb and whole-body postures are critical factors associated with knee joint loading [8, 14, 86-89]. Consequently, several investigations have examined the effect of COD angle on associative biomechanical risk factors connected to increased risk of injury (Table 1). Cortes et al. [29] observed greater knee valgus angles, greater peak posterior GRFs, greater internal varus moments, and lower knee flexion angles during a $180^{\circ}$ pivot compared to a $45^{\circ}$ cut. Likewise, McLean et al. [20] also reported greater knee valgus angles during a $180^{\circ}$ pivot compared to a $45^{\circ}$ cut. Additionally, Schreurs et al. [22] documented a reduction in knee flexion angle with sharper CODs, and Havens and Sigward [26] reported the knee was primarily involved in absorption during the deceleration phase of sharper cuts. These findings are concerning because extended knee positions can increase anterior tibial shear forces [67], thus increasing ACL strain [68-72]. Moreover, greater knee valgus angles $[27,32,37,38,90]$ and posterior GRFs [27, 36] are linked to increased KAMs, which can increase ACL strain [68, 91-93]. Collectively, these findings are problematic because KAMs have been shown to prospectively predict non-contact ACL injury in female adolescent athletes [78]. Furthermore, extended knee postures, greater knee abduction angles and greater GRFs have been identified as mechanisms and characteristics linked to ACL injuries [7, $8,10,14,94]$.

Sigward, Cesar and Havens [27] reported increases in KAMs and GRFs during a $110^{\circ}$ cut versus a $45^{\circ}$ cut, and differences in hip abduction and internal rotation angle (Table 1). Specifically, KAMs on average were 2.4 times greater during the $110^{\circ}$ cut. This finding is corroborated by Besier et al. [28], who reported greater knee valgus loading when comparing $60^{\circ}$ sidesteps to $30^{\circ}$ sidesteps, and corroborated by Havens and Sigward [30], who demonstrated greater KAMs during $90^{\circ}$ cuts compared to $45^{\circ}$ cuts (Table 1 ). The increased KAMs and knee joint loads could be explained by the fact the KAMs are influenced by the magnitude of the GRF, and the moment arm in the frontal plane [32]. Greater GRF magnitudes [19, 25, 27, 29] and lower knee flexion angles [22, 27, 29] have been observed with sharper CODs, yet greater moment arms could be created due to greater hip abduction [26, 27] and greater ML COM-COP distances 
(i.e. lateral foot plant), which have been reported in sharper CODs [25]. This can have the effect of moving the force vector laterally to the knee, thus creating a larger moment arm relative to the knee joint centre [30, 38, 39]. Consequently, this suggests sharper CODs predispose athletes to greater knee joint loading and subsequent risk of injury, but sharp CODs are unavoidable in sport, and typically performed to evade or pursue opponents or a ball, particularly in unanticipated environments. Thus, it is imperative that athletes have the physical capacity to tolerate the knee joint loading associated with sharper directional changes [58, 81-84] and perform these actions with optimal mechanics $[32,37,38$, $44,45]$.

Substantiating the findings of previous studies [27-30], Schreuers et al. [22] demonstrated sharper CODs $\left(90^{\circ}, 135^{\circ}\right.$ and $180^{\circ}$ ) compared to $45^{\circ}$ cuts resulted in greater KAMs in both male and female athletes. However, a noteworthy observation was the stabilisation and lack of differences in KAMs between $90^{\circ}, 135^{\circ}$ and $180^{\circ}$ CODs (Table 1), indicating that these tasks may have a similar risk of injury. The authors hypothesised the differences could be attributed to differences in the preliminary steps and knee and trunk positioning relative to the direction of travel. A shortcoming of this study, however, was the authors failed to examine trunk kinematics and did not examine the braking force characteristics of the PFC. Previous studies have shown that the PFC plays an integral role in deceleration prior to executing sharp CODs, such as $60^{\circ}-90^{\circ}$ cuts and $135^{\circ}-180^{\circ}$ turns $[25$, $34-38,58-61]$, and athletes tend to lean and rotate their trunk towards the direction of travel when changing direction $[26,40]$. As such, further research comprehensively examining whole-body kinetics and kinematics during the FFC and PFC between different angled CODs is warranted.

Athletes unable to recognise and identify kinematic cues from their opposition or passage of play sooner (lacking perceptual-cognitive ability) $[43,63,83,95,96]$, in conjunction with sub-optimal physical capacity $[58,81-84]$ to execute the directional change, may be placed at greater risk of injury, especially during sharper directional changes. However, an athlete who can identify cues earlier could be able to make whole-body postural adjustments for the upcoming movement and pre-activate the required lower-limb and trunk musculature to efficiently execute the direction change, while potentially reducing knee joint loading and subsequent risk of injury [62, 97]. Further research is needed to confirm whether perceptual training (vision training) can enhance deceleration strategies (steps prior to COD) and postural adjustments to facilitate more effective deceleration and safer mechanics to reduce risk of injury and improve performance.

It should be noted that the studies that have investigated the effect of angle on COD biomechanics (Table 1) have all been performed in laboratory settings, with the exception of Hader et al. [23, 24], thus the tasks may not truly reflect competitive situations in multidirectional sport. Nonetheless, when prescribing COD training, athletes should perform shallow CODs before progressing to sharper CODs, due to the elevated knee joint loading and GRFs (Table 1). This is strongly recommended when working with novice or weak athletes (one repetition maximum back squat $\leq 1.5 \times$ body mass), who have limited experience with structured COD training, or may not have the strength capacity to efficiently absorb and tolerate the greater forces and loading associated with sharper CODs [81, 98-101]. Additionally, a progression from shallow to sharper CODs is also advocated for athletes rehabilitating and returning to sport from previous injury.

\subsection{Effect on Muscle Activation and Estimated Energy Expenditure}

Research from Hader et al. [23] has shown that estimated energy expenditure (EEE) and muscle activity demands of CODs are angle dependent (Table 1). The authors found that as COD angle increased from a straight run to $45^{\circ}$ and $90^{\circ}$, the EEE decreased. Furthermore, greater muscle activity (EMG amplitude) of the vastus lateralis and biceps femoris during the sharper cut was also observed. The quadriceps are considered essential for the eccentric contractions during the deceleration phase [23, 61, 102], where GRFs are typically higher during sharper CODs [19, 25, 27, 29]. In addition, hamstring activity is required to stabilise the knee and prevent anterior translation of the tibia, thus protecting the ACL [51, 82, 103, 104]. Collectively, co-contraction of the knee flexors and extensors is required to tolerate the large external loads at the knee when changing direction [51]. As such, due to the greater muscle activations of the knee flexors and extensors during sharper CODs, practitioners should aim to develop knee flexor and extensor strength, in particular eccentric strength [41, 58, 81, 98, 105-109], in athletic populations where CODs are fundamental movements. This may assist and facilitate a greater capacity to absorb the high forces $[19,25,27,29]$ and tolerate the greater knee joint loading [22, 27-30] associated during the deceleration phases of CODs. Furthermore, improvements in strength capacity may improve an athlete's ability to produce greater braking and propulsive forces and impulse [41, 81, $107,110]$, which are determinants of faster performance [41, $59,60,106]$, thus positively enhancing COD performance.

\subsection{Effect of COD Angle on Ground Contact Time}

Differing from the PFC, the plant step (FFC) contains both a braking and a propulsive force component within the forcetime curve [36, 83]. COD angle influences the braking and propulsive forces of the plant step $[19,25,27,29]$ (Table 1); 
however, COD angle also directly influences GCT [25, 31, 32, 34-36, 40-42, 52, 59, 106, 111-113], thus impacting braking and propulsive impulse during the COD. Table 2 presents normative GCTs reported across the biomechanical literature, illustrating an increased GCT with sharper CODs, which could be explained by the greater braking and propulsive force and impulse requirements to change momentum [23-26]. Furthermore, Condello et al. [52] observed a strong relationship between GCT and executed cutting angle ( $r=$ $0.60-0.79, p<0.05$ ). Subsequently, this has large implications for the design of strength and conditioning programs and exercise selection for the enhancement of COD performance, which will be discussed in Sect. 6. It should also be noted that approach velocity also affects GCT; this is discussed in Sect. 3.

\subsection{COD Task Execution: Intended Angle does not Reflect Executed Angle}

Numerous biomechanical investigations select and investigate specific angled direction changes thought to be a key mechanism of ACL injuries or pivotal movements in that sport $[25,31,32,34-36,40-42,52,59,106,111-113]$ in an attempt to improve our understanding of the mechanics that influence injury risk and performance. However, although the athletes in these investigations are instructed to perform a directional change of a specific angle (theoretical path), with lines marked on the floor to guide the athlete, the path of travel may not reflect the actual executed angle of COD [28, 31, 52, 55, 114, 115] (Table 3). For example, Vanrenterghem et al. [31] demonstrated COM travel was not achieved during a sidestep, and this was exacerbated with increased running velocities, suggesting there may be an 'angle-velocity trade-off' when executing CODs (Table 3) [19]. These findings corroborate previous studies that have also demonstrated the executed COD angle is smaller than the intended COD angle $[52,55,66,116]$ (Table 3). Additionally, Condello et al. [52] inspected the real path of travel during $60^{\circ}$ cuts and found athletes performed a rounded or sharp execution of the COD, observing a large correlation ( $r=0.60-0.79, p<0.05$ ) between performance cutting angle and GCTs; this highlighted that sharper CODs were attributed to longer GCTs, therefore increasing braking and propulsive impulse potential.

Collectively, based on the abovementioned findings (Table 3), in order to achieve the intended direction of travel, the following foot contacts after the plant foot contact (which initiates the COD) must be involved in redirecting the athlete $[53,61,66,117]$. This concept is substantiated by Rovan et al. [66], who found the following step and two steps after the plant foot contact were involved in facilitating $30^{\circ}$, $60^{\circ}, 90^{\circ}, 120^{\circ}, 150^{\circ}$ and $180^{\circ} \mathrm{CODs}$ based on global positioning system data and qualitative analysis using high speed cameras. Interestingly, the directional change was initiated one step before the plant foot contact, highlighting the role of the PFC for pre-planned CODs. Consequently, the results of Rovan et al. [66] highlight the steps following and prior to the plant foot, and also play an integral role when changing direction, therefore confirming Andrews et al. [61] 's early description of CODs as a multi-step action. Current COD technique and coaching guidelines typically focus on the plant step (FFC) [3, 118-121]; however, practitioners should not only coach the plant step when changing direction, but coach a multi-step action taking into account the step(s) prior and step(s) following the plant step. Future investigations that comprehensively examine CODs as a multi-step action (via 3D motion analysis of PFC, plant foot, and following step) are required to improve our understanding of optimal COD techniques.

\section{Effect of Velocity on COD Biomechanics}

Various standardised approach velocities have been administered when exploring COD biomechanics including: $3.0 \mathrm{~m} \cdot \mathrm{s}^{-1}[28,49,51,53], 3.5 \mathrm{~m} \cdot \mathrm{s}^{-1}[122], 3.6-4.4 \mathrm{~m} \cdot \mathrm{s}^{-1}$ $[36,37], 4.0 \mathrm{~m} \cdot \mathrm{s}^{-1}[47], 4.0-5.0 \mathrm{~m} \cdot \mathrm{s}^{-1}[36,38,123]$, $4.0-5.5 \mathrm{~m} \cdot \mathrm{s}^{-1}$ [27], $4.5 \mathrm{~m} \cdot \mathrm{s}^{-1}$ [45], 4.5-5.0 $\mathrm{m} \cdot \mathrm{s}^{-1}[43,124]$, $4.5-5.5 \mathrm{~m} \cdot \mathrm{s}^{-1}[27,90,125,126], 5.5-7.0 \mathrm{~m} \cdot \mathrm{s}^{-1}[39,127]$ or as fast as possible $[25,30,42,56]$. However, approach velocity is a critical factor influencing COD biomechanical demands [31-35] (Table 4), which should be acknowledged when interpreting COD biomechanical research and coaching COD technique.

\subsection{Faster Approach Velocities Increase Knee Joint Loading during CODs}

Vanrenterghem et al. [31] reported increases in knee valgus loading during $45^{\circ}$ sidesteps from faster running velocities $\left(4\right.$ and $5 \mathrm{~m} \cdot \mathrm{s}^{-1}$ ) compared to slower velocities ( 2 and $\left.3 \mathrm{~m} \cdot \mathrm{s}^{-1}\right)$. This result is corroborated by previous studies that have reported greater KAMs between faster and slower $60^{\circ}$ sidesteps [34], and $135^{\circ} \mathrm{v}$ cuts with increased approach velocities [35] (Table 4). Additionally, Kristianslund et al. [32] reported approach speed to be a predictor of KAMs during a sports-specific sidestep in handballers. These findings are noteworthy because knee abduction loading can increase strain on the ACL $[68,75,92,93]$ and prospective research has identified KAMs as a predictor of noncontact ACL injury in female adolescent athletes [78]. Furthermore, video analysis investigations have characterised non-contact ACL injuries to occur from CODs with high approach velocities in handball [8] and rugby [10]. Having athletes perform directional changes from slower approach velocities will, indeed, alleviate knee joint loading, but this 
will compromise COD performance as approach velocity is a determinant of faster COD performance $[24,58]$; thus, athletes will be highly unlikely to sacrifice performance at the expense of reduced knee joint loading. Therefore, practitioners and athletes must acknowledge from a technique perspective the 'performance-injury conflict' when coaching and performing CODs as fast as possible and ensure athletes have the optimal COD mechanics [32, 37, 38, 44, 45] and physical capacity to tolerate the associative knee joint loading [58, 81-84]. Further research into the most effective training modalities for the optimisation of COD performance and minimising knee joint loading are required.

\subsection{Effect on COD Kinetics and Kinematics}

While approach velocity is a critical factor on knee joint loading, it also directly influences the kinetic and kinematic profiles demonstrated by athletes (Table 4). Vanrenterghem et al. [31] documented significant increases in peak posterior GRF, ML GRF and concurrent reductions in GCT with increased approach velocities, while knee flexion angles at touchdown were only significantly different at $5 \mathrm{~m} \cdot \mathrm{s}^{-1}$. Similarly, Dai et al. [33] also demonstrated a significant decrease in GCT and increases in peak posterior GRF, knee extension moment at peak posterior GRF, knee valgus angle and varus moment at peak posterior GRF, knee joint stiffness, and knee flexion angle during $45^{\circ}$ sidesteps, when comparing maximum speed versus perceived $60 \%$ (Table 4). Kimura and Sakurai [34] also observed significantly shorter GCTs between faster and slower $60^{\circ}$ cuts (Table 4 ). Collectively, these studies highlight the kinetic and kinematic differences during the directional changes with increases in entry velocity, which highlights the difficulty in comparing the results between studies in the literature. Therefore, the injury risk associative studies should be interpreted with respect to the approach velocities used for the COD task, because the velocities examined $\left(\leq 4 \mathrm{~m} \cdot \mathrm{s}^{-1}\right)$ may not have been high enough to elicit hazardous knee joint loading connected to increased risk of ACL injury [31, 34, 35].

\subsection{Role of the PFC}

Changing direction is described as a multi-step action [61], with research indicating the step(s) prior to the COD are pivotal in deceleration and initiating effective CODs [34-38, $53,58-60,64,66,128-133]$. Specifically, researchers have shown that the greater braking force characteristics demonstrated in the PFC during COD can alleviate knee joint loading [36-38] and also facilitate faster turning performance [58-60]; however, only two studies have examined the effect of approach velocity on PFC biomechanics. Kimura and Sakurai [34] compared faster and slower $60^{\circ}$ sidesteps, reporting greater posterior impulse, shorter GCTs and greater peak external flexion moments in the PFC during the fast condition (Table 4). Similarly, Nedergaard et al. [35] observed greater trunk decelerations at higher approach velocities over the PFC and ipsilateral foot contact during a $135^{\circ} \mathrm{v}$ cut. Additionally, this was accompanied with greater peak ankle and knee velocities during both of the aforementioned foot contacts, which are suggested to provide an indirect indication of force absorption [67, 134].

Collectively, the results of the aforementioned studies highlight the role of deceleration over the PFC, and the preceding footfalls, to facilitate effective CODs. The PFC not only plays a pivotal role during sharper CODs [25, 34-38, $59,60,66]$, but is fundamental in the execution of directional changes from high approach velocities [34, 35]. This finding is unsurprising as faster entries would require greater braking forces and braking impulse over the PFC and steps prior (change in momentum), to reduce the momentum and entry velocity prior to the COD. Therefore, biomechanists should investigate the PFC when examining COD biomechanics from high approach velocities and sharper CODs for greater insight into the braking force characteristics and mechanisms required to effectively change direction. Furthermore, practitioners are encouraged to coach a deceleration strategy that emphasises braking forces over several gait cycles, in particular the PFC, when coaching sharp CODs or sharp CODs from fast approach velocities. Previous researchers have shown technique changes and reduced knee joint loading in cutting [44] and turning [135] from a 6-week (two sessions per week) COD technique modification intervention. Further research is needed to confirm whether longitudinally coaching PFC-dominant deceleration strategies are effective for improving COD performance and reducing knee joint loading.

\section{Effect of Velocity and Angle on COD Performance}

Straight line sprint speed is suggested to be a determinant of COD performance as it would be advantageous to enter and exit the COD as fast as possible $[119,136]$. However, there is a paucity of studies that have examined an athlete's horizontal velocity before, during and after a COD [24, 58]. Hader et al. [24] assessed COM velocity during a $45^{\circ}$ and $90^{\circ}$ cut from a $10-\mathrm{m}$ approach using laser speed guns, reporting the minimum speed during the COD was largely associated with cutting performance for both tasks, and peak acceleration and peak speed also contributed to faster performance. These findings highlight the importance of maintaining and minimising the decline in velocity prior to and during a $45^{\circ}$ and $90^{\circ}$ cut for faster performance. Thus, coaching strategies that encourage the maintenance of velocity by limiting preliminary deceleration may be warranted for faster 
cutting performance. However, it should be noted that some deceleration (reductions in velocity) will be present when changing direction $[24,25]$, in particular for sharper $90^{\circ}$ cuts (Fig. 1), but the ability to tolerate the greater velocities may facilitate faster performance.

Examining a sharper $180^{\circ} \mathrm{COD}$ in female soccer players, Jones et al. [58] inspected the horizontal velocity of COM from the approach of the PFC to the exit of the FFC, using the methods described by Vanrenterghem et al. [137]. Faster performance was inversely associated $(r=-0.484$, $r^{2}=23 \%$ ) with greater approach velocities (i.e. horizontal model COM velocity at the start of the PFC). Notably, eccentrically stronger (knee extensor peak torque) soccer players demonstrated faster COD performance $(d=-2.09)$, greater approach velocities $(d=1.27)$, and greater reductions in velocity during the PFC $(d=-0.94)$ in comparison to weaker, while greater peak and average horizontal GRFs over the PFC were also displayed by stronger athletes $(d=1.00-1.23)$. These findings suggest there may be an interaction between strength and speed in the facilitation of faster COD performance. Based on the results that eccentrically stronger athletes demonstrated better deceleration abilities, approached with greater velocities, and produced greater change in velocities and braking forces, the authors introduced a concept of 'self-regulation' regarding approach velocity (i.e. 'a player approaches faster based on the deceleration load they know/feel they can tolerate'). Nonetheless, the ability to approach a $180^{\circ}$ turn quickly and reduce the velocity over the PFC into the FFC is integral for faster performance, while the ability to decelerate efficiently is underpinned by eccentric strength capacity.

The majority of investigations have examined the influence of angle on injury risk factors during CODs [19, 22, $25,27,29]$; however, a paucity of research exists examining the influence of angle on COD performance, whereby the optimal techniques for faster performance will most likely be angle dependent [21, 24, 26, 30]. Rouissi et al. [138] examined completion times and COD deficit during a range of 10-m COD tasks (5-m entry and exit) of different angles $\left(45^{\circ}, 90^{\circ}, 135^{\circ}\right.$ and $\left.180^{\circ}\right)$, noting a trend in increasing completion times and COD deficits in male soccer players as COD angle increased. Likewise, Schreurs et al. [22] reported significant increases in completion time as COD angle $\left(45^{\circ}\right.$, $90^{\circ}, 135^{\circ}$ and $180^{\circ}$ ) increased in male and female athletes. These findings are unsurprising because as the COD angle increases, greater reductions in velocity (change in momentum) are required [23-25], thus increasing the demands for preliminary deceleration, which typically occur over greater distances [23-25]. In addition, GCTs also increase with sharper CODs (Table 2); therefore, the combination of deceleration and longer GCTs most likely explain the longer completion times associated with sharper CODs.
The technique required for faster COD performance is also angle dependent [21, 24, 26, 30]. For example, Havens and Sigward [30] found that the determinants for $45^{\circ}$ and $90^{\circ}$ cutting performance differed between tasks. Faster $45^{\circ}$ completion times were associated with greater hip sagittal power, hip extensor moments and greater ML COM-COP distances. Conversely, faster $90^{\circ}$ cut performance was associated with greater hip frontal power and ML GRI, indicating a greater reliance on frontal plane biomechanics for $90^{\circ}$ cutting, in contrast to sagittal plane determinants for $45^{\circ}$ cutting. In addition, Hader et al. [24] identified that the minimum speed during the COD was a predictor of faster cutting performance. Therefore, when maintaining velocity is essential such as running around the bases in baseball/ softball or possessing greater momentum in collision sports such as rugby and American football is desired, a rounded or shallow COD is recommended due to the shorter GCTs and minimal reductions in velocity [21, 24, 52]. Conversely, when the aim is to execute sharper CODs, in particular $\geq 60^{\circ}$ to evade an opponent or turn in response to a ball or opponent, substantial deceleration over several gait cycles prior to the plant foot contact will undoubtedly be required $[25,34-38,58-61,66]$.

\section{Changing Direction: An Angle-Velocity Trade-Off During Cutting}

In multidirectional sport it would be advantageous to perform sharp cuts from high approach velocities with minimal reductions in velocity [5, 24, 132]; however, an angle-velocity trade-off exists when performing cutting manoeuvres [19, 31, 55] (Table 3). Vanrenterghem et al. [31] reported a reduction in task execution (executed cutting angle) with increased running velocities during $45^{\circ}$ sidesteps (Table 3 ). Similarly, Suzuki et al. [55] found greater cutting angles with a sidestep technique compared to a crossover cut during an intended $90^{\circ} \mathrm{COD}$, but a greater reduction in velocity was also demonstrated (Table 3). Furthermore, Schot et al. [19] stated that in pilot work, in order to achieve a $90^{\circ}$ cut as fast as possible, subjects would often require three to five steps to perform the directional change, but this resulted in a rounded COD. Therefore, it is evident a trade-off between angle and velocity exists when changing direction, whereby executing CODs from fast approach velocities reduces task execution (executed cutting angle), and vice versa. This finding has large implications for the deceleration requirements for $\mathrm{COD}$, as the deceleration strategy to execute the COD effectively is governed by the angle and velocity at which the COD is performed.

Maintaining velocity and greater approach velocities are identified as determinants of COD performance [24, 58] and, therefore, may be encouraged when coaching cutting 
technique. However, faster approach velocities may compromise the executed cutting angle and also increase knee joint loading, which creates a conflict for practitioners and athletes. As such, practitioners must identify the aim of the COD attribute they are aiming to develop (i.e. velocity maintenance, COD angle execution, or balance of the two factors), and consider the context and specific movement demands of the sport. For example, in sports where the maintenance of velocity is essential when performing COD such as running around the bases in softball/baseball, or a subtle COD to maintain momentum in collision sports such as rugby and American football, a rounded or shallow COD, with high approach velocities, thus momentum and shorter GCTs may be warranted [21, 24, 52]. Where a subtle COD is necessary, a crossover cut is recommended due to greater velocity maintenance, and this technique results in shorter GCTs [55, 102, 117] (Fig. 1). Conversely, scenarios where sharper cuts are necessary to evade (deceive) and create larger separation distances from opponents, a slower approach or reduction in approach velocity may be necessary (potentially over several gait cycles), and a sidestep strategy to facilitate an effective sharp COD is recommended [55, 102, 117] (Fig. 1).

\section{Implications of Change of Direction Angle for Training Design and Exercise Selection}

The determinants of COD performance are multifaceted $[2,4,83,136]$; however, physical attributes such as rate of force development and reactive strength (fast or slow stretchshortening cycle abilities) are fundamental qualities underpinning COD performance $[2,4,83,136]$, while the large levels of relative lower body loading associated with COD $[28,32,37,44,45]$ actions must also be acknowledged. As such, training modalities that enhance COD performance and an athlete's robustness to tolerate the loading associated with CODs are of great interest to practitioners.

Table 2 outlines training and exercise selection recommendations for athletes who participate in multidirectional sport, and we specifically introduce a novel concept of selecting training exercises in accordance to COD angle due its subsequent effect on GCTs. Lower limb plyometric training is an effective training modality for enhancing COD performance [139-141], due to the similarities in GCT and the involvement of an eccentric-concentric coupling action [111, 142]. Specifically, lower limb plyometric exercises provide a stimulus resulting in high power outputs, high ankle flexor moments in short GCTs [143], increased force output and stretch shortening cycle (SSC) efficiency [139], all of which are important components for faster COD performance. Furthermore, plyometric and jump-landing training with appropriate feedback can also enhance lower limb control, reduce knee valgus and reduce impact forces and torques [84, 144-147], thus reducing the potential risk of injury. Table 2 provides exercise selection recommendations dependent on COD angle: for example, in light of the GCTs reported for shallow CODs $\left(\leq 60^{\circ}\right)$ (Table 2), fast SSC (fast reactive strength $<0.25 \mathrm{~s}$ ) exercises are recommended [148]. Conversely, for sharper CODs $\left(\geq 135^{\circ}\right)$, slow SSC actions and ballistic exercises (slow reactive strength $>0.25 \mathrm{~s}$ ) are recommended, whereas a combination of fast and slow SSC exercises are recommended for $90^{\circ}$ cuts, due to bordering fast and slow SSC classification ( 0.25-0.35 s) [148].

Cutting is a unilateral, multiplanar movement, and dependent on the ability to generate ML propulsive force and impulse [25, 30, 38], hip frontal plane power [30] and ankle power [40]. Therefore, plyometric exercises should not only be performed in the sagittal plane emphasizing vertical displacement, but also performed in several directions [139] in the frontal and transverse plane emphasising horizontal displacement [111]. In particular, unilateral plyometrics (training recommendations in Table 2) should be incorporated into the strength and conditioning program due to the similarity in the orientation of force application and push-off action to cutting [136]. However, practitioners should be aware that landings in the frontal plane may have higher task complexity and have a higher risk of knee injury in comparison to forward and diagonal landings [149].

Athletes should ideally possess a solid foundation of strength (one repetition maximum back squat $\geq 1.5 \times$ body mass) before performing complex and higher intensity plyometrics $[81,101,118]$, while eccentric strength capacity is also fundamental for successful COD performance and tolerating the large joint loading [41, 58, 81, 98, 105-109]. Shorter GCTs have been identified as determinants of faster COD performance $[40,42,59,112]$; thus, the aims of the aforementioned training recommendations are to reduce braking and propulsive force duration (total duration), but simultaneously increase braking and propulsive forces, resulting in a tall and thin impulse, in contrast to a short and wide impulse. In summary, practitioners should understand the implications of COD angle on GCT and should therefore select exercises according to COD angle and task demands. Moreover, practitioners are encouraged to implement a holistic multi-component strength and conditioning programme that integrates strength, plyometric, trunk (core) and COD technique training for the enhancement of COD performance and injury risk reduction $[44,81,84,87,150]$.

\section{Conclusions}

The biomechanical demands of CODs are 'angle' and 'velocity dependent' and are both critical factors that influence the technical execution of the COD, deceleration and 
reacceleration requirements, knee joint loading, and lower limb muscle activity. Thus, these two factors regulate the progression and regression in COD intensity. Specifically, faster and sharper CODs increase knee joint loading, but are also required for successful performance creating a 'performance-injury conflict' from a technique perspective; however, this conflict can be mediated by an athlete's physical capacity (i.e. ability to rapidly produce force and neuromuscular control) and performing the COD with optimal mechanics. Furthermore, an 'angle-velocity trade-off' exists during CODs, whereby faster approaches compromise the execution of the intended COD; this is influenced by an athlete's physical capacity. Therefore, practitioners and researchers should acknowledge and understand the implications of angle and velocity on COD biomechanics when: (1) interpreting biomechanical research; (2) coaching COD technique; (3) designing and prescribing COD training and injury reduction programs; (4) conditioning athletes to tolerate the physical demands of directional changes; (5) screening COD technique; and (6) progressing and regressing COD intensity, specifically when working with novice or previously injured athletes who are rehabilitating from an injury.

\section{Compliance with Ethical Standards}

Funding No sources of funding were used to assist in the preparation of this article.

Conflict of Interest Thomas Dos'Santos, Christopher Thomas, Paul Comfort and Paul Jones declare that they have no conflicts of interest relevant to the content of this review.

Open Access This article is distributed under the terms of the Creative Commons Attribution 4.0 International License (http://creativeco mmons.org/licenses/by/4.0/), which permits unrestricted use, distribution, and reproduction in any medium, provided you give appropriate credit to the original author(s) and the source, provide a link to the Creative Commons license, and indicate if changes were made.

\section{References}

1. Bloomfield J, Polman R, Donoghue P. Physical demands of different positions in FA Premier League soccer. J Sports Sci Med. 2007;6(1):63-70.

2. Sheppard JM, Dawes JJ, Jeffreys I, Spiteri T, Nimphius S. Broadening the view of agility: a scientific review of the literature. $\mathrm{J}$ Aust Strength Cond. 2014;22(3):6-25.

3. Nimphius S. Increasing agility. In: Joyce D, Lewindon D, editors. High-performance training for sports. Champaign, Illionois: Human Kinetics; 2014. p. 185-98.

4. Young WB, Dawson B, Henry GJ. Agility and change-ofdirection speed are independent skills: implications for training for agility in invasion sports. Int J Sports Sci Coach. 2015;10(1):159-69.
5. Faude O, Koch T, Meyer T. Straight sprinting is the most frequent action in goal situations in professional football. J Sports Sci. 2012;30(7):625-31.

6. Karcher C, Buchheit M. On-court demands of elite handball, with special reference to playing positions. Sports Med. 2014;44(6):797-814.

7. Walden M, Krosshaug T, Bjorneboe J, Andersen TE, Faul O, Hagglund M. Three distinct mechanisms predominate in noncontact anterior cruciate ligament injuries in male professional football players: a systematic video analysis of 39 cases. Br J Sports Med. 2015;49(22):1452-60.

8. Olsen O-E, Myklebust G, Engebretsen L, Bahr R. Injury mechanisms for anterior cruciate ligament injuries in team handball a systematic video analysis. Am J Sports Med. 2004:32(4):1002-12.

9. Brophy RH, Stepan JG, Silvers HJ, Mandelbaum BR. Defending puts the anterior cruciate ligament at risk during soccer: a gender-based analysis. Sports Health. 2015;7(3):244-9.

10. Montgomery C, Blackburn J, Withers D, Tierney G, Moran C, Simms C. Mechanisms of ACL injury in professional rugby union: a systematic video analysis of 36 cases. Br J Sports Med. 2018;52(15):994-1001.

11. Cochrane JL, Lloyd DG, Buttfield A, Seward H, McGivern J. Characteristics of anterior cruciate ligament injuries in Australian football. J Sci Med Sport. 2007;10(2):96-104.

12. Faude O, Junge A, Kindermann W, Dvorak J. Injuries in female soccer players a prospective study in the german national league. Am J Sports Med. 2005;33(11):1694-700.

13. Boden BP, Dean GS, Feagin JA, Garrett WE. Mechanisms of anterior cruciate ligament injury. Orthopedics. 2000;23(6):573-8.

14. Koga H, Nakamae A, Shima Y, Iwasa J, Myklebust G, Engebretsen L, et al. Mechanisms for noncontact anterior cruciate ligament injuries knee joint kinematics in 10 injury situations from female team handball and basketball. Am J Sports Med. 2010;38(11):2218-25.

15. Robinson G, O'Donoghue $P$, Nielson $P$. Path changes and injury risk in English FA Premier League soccer. Int J Perform Anal Sport. 2011;11(1):40-56.

16. Sweeting AJ, Aughey RJ, Cormack SJ, Morgan S. Discovering frequently recurring movement sequences in team-sport athlete spatiotemporal data. J Sports Sci. 2017;35(24):2439-45.

17. Taylor JB, Wright AA, Dischiavi SL, Townsend MA, Marmon AR. Activity demands during multi-directional team sports: a systematic review. Sports Med. 2017;47(12):2533-51.

18. Wheeler KW, Askew CD, Sayers MG. Effective attacking strategies in rugby union. Eur J Sport Sci. 2010;10(4):237-42.

19. Schot P, Dart J, Schuh M. Biomechanical analysis of two changeof-direction maneuvers while running. J Orthop Sports Phys Therapy. 1995;22(6):254-8.

20. McLean SG, Walker KB, van den Bogert AJ. Effect of gender on lower extremity kinematics during rapid direction changes: an integrated analysis of three sports movements. J Sci Med Sport. 2005;8(4):411-22.

21. Nimphius S, Callaghan SJ, Bezodis NE, Lockie RG. Change of direction and agility tests: challenging our current measures of performance. Strength Cond J. 2018;40(1):26-38.

22. Schreurs MJ, Benjaminse A, Lemmink KA. Sharper angle, higher risk? The effect of cutting angle on knee mechanics in invasion sport athletes. J Biomech. 2017;63:144-50.

23. Hader K, Mendez-Villanueva A, Palazzi D, Ahmaidi S, Buchheit M. Metabolic power requirement of change of direction speed in young soccer players: not all is what it seems. PLoS One. 2016;11(3): e0149839.

24. Hader K, Palazzi D, Buchheit M. Change of direction speed in soccer: how much braking is enough? Kineziologija. 2015;47(1):67-74. 
25. Havens KL, Sigward SM. Whole body mechanics differ among running and cutting maneuvers in skilled athletes. Gait Posture. 2014;42(3):240-5.

26. Havens KL, Sigward SM. Joint and segmental mechanics differ between cutting maneuvers in skilled athletes. Gait Posture. 2015;41(1):33-8.

27. Sigward SM, Cesar GM, Havens KL. Predictors of frontal plane knee moments during side-step cutting to 45 and 110 degrees in men and women: implications for anterior cruciate ligament injury. Clin J Sport Med. 2015;25(6):529-34.

28. Besier TF, Lloyd DG, Cochrane JL, Ackland TR. External loading of the knee joint during running and cutting maneuvers. Med Sci Sports Exerc. 2001;33(7):1168-75.

29. Cortes N, Onate J, Van Lunen B. Pivot task increases knee frontal plane loading compared with sidestep and drop-jump. J Sports Sci. 2011;29(1):83-92.

30. Havens KL, Sigward SM. Cutting mechanics: relation to performance and anterior cruciate ligament injury risk. Med Sci Sports Exerc. 2015;47(4):818-24.

31. Vanrenterghem J, Venables E, Pataky T, Robinson MA. The effect of running speed on knee mechanical loading in females during side cutting. J Biomech. 2012;45(14):2444-9.

32. Kristianslund E, Faul O, Bahr R, Myklebust G, Krosshaug T. Sidestep cutting technique and knee abduction loading: implications for ACL prevention exercises. Br J Sports Med. 2014;48(9):779-83.

33. Dai B, Garrett WE, Gross MT, Padua DA, Queen RM, Yu B. The effect of performance demands on lower extremity biomechanics during landing and cutting tasks. J Sport Health Sci. 2016;43(9):1680.

34. Kimura K, Sakurai S. A sidestep cut preparation strategy decreases the external load applied to the knee joint. Int J Sport Health Sci. 2013;11:109-17.

35. Nedergaard NJ, Kersting U, Lake M. Using accelerometry to quantify deceleration during a high-intensity soccer turning manoeuvre. J Sports Sci. 2014;32(20):1897-905.

36. Jones PA, Herrington L, Graham-Smith P. Braking characteristics during cutting and pivoting in female soccer players. J Electromyogr Kinesiol. 2016;30:46-54.

37. Jones PA, Herrington LC, Graham-Smith P. Technique determinants of knee abduction moments during pivoting in female soccer players. Clin Biomech. 2016;31:107-12.

38. Jones PA, Herrington LC, Graham-Smith P. Technique determinants of knee joint loads during cutting in female soccer players. Hum Mov Sci. 2015;42:203-11.

39. Sigward SM, Powers CM. Loading characteristics of females exhibiting excessive valgus moments during cutting. Clin Biomech. 2007;22(7):827-33.

40. Marshall BM, Franklyn-Miller AD, King EA, Moran KA, Strike S, Falvey A. Biomechanical factors associated with time to complete a change of direction cutting maneuver. J Strength Cond Res. 2014;28(10):2845-51.

41. Spiteri T, Cochrane JL, Hart NH, Haff GG, Nimphius S. Effect of strength on plant foot kinetics and kinematics during a change of direction task. Eur J Sport Sci. 2013;13(6):646-52.

42. Sasaki S, Nagano Y, Kaneko S, Sakurai T, Fukubayashi T. The relationship between performance and trunk movement during change of direction. J Sports Sci Med. 2011;10(1):112-8.

43. Weinhandl JT, Earl-Boehm JE, Ebersole KT, Huddleston WE, Armstrong BS, O'connor KM. Anticipatory effects on anterior cruciate ligament loading during sidestep cutting. Clin Biomech. 2013;28(6):655-63.

44. Dempsey AR, Lloyd DG, Elliott BC, Steele JR, Munro BJ. Changing sidestep cutting technique reduces knee valgus loading. Am J Sports Med. 2009;37(11):2194-200.
45. Dempsey AR, Lloyd DG, Elliott BC, Steele JR, Munro BJ, Russo KA. The effect of technique change on knee loads during sidestep cutting. Med Sci Sports Exerc. 2007;39(10):1765-73.

46. Jamison ST, Pan X, Chaudhari AMW. Knee moments during runto-cut maneuvers are associated with lateral trunk positioning. J Biomech. 2012;45(11):1881-5.

47. Fuerst P, Gollhofer A, Gehring D. Preparation time influences ankle and knee joint control during dynamic change of direction movements. J Sports Sci. 2017;35(8):762-8.

48. Sigward SM, Pollard CD, Havens KL, Powers CM. The influence of sex and maturation on knee mechanics during side-step cutting. Med Sci Sports Exerc. 2012;44(8):1497-503.

49. Besier TF, Lloyd DG, Ackland TR, Cochrane JL. Anticipatory effects on knee joint loading during running and cutting maneuvers. Med Sci Sports Exerc. 2001;33(7):1176-81.

50. Iguchi J, Tateuchi $\mathrm{H}$, Taniguchi $\mathrm{M}$, Ichihashi $\mathrm{N}$. The effect of sex and fatigue on lower limb kinematics, kinetics, and muscle activity during unanticipated side-step cutting. Knee Surg Sports Traumatol Arthrosc. 2014;22(1):41-8.

51. Besier TF, Lloyd DG, Ackland TR. Muscle activation strategies at the knee during running and cutting maneuvers. Med Sci Sports Exerc. 2003;35(1):119-27.

52. Condello G, Kernozek TW, Tessitore A, Foster C. Biomechanical analysis of a change-of-direction task in college soccer players. Int J Sports Physiol Perform. 2016;11(1):96-101.

53. Jindrich DL, Qiao M. Maneuvers during legged locomotion. Chaos: an interdisciplinary. J Nonlinear Sci. 2009;19(2):026105.

54. Tanikawa H, Matsumoto H, Komiyama I, Kiriyama Y, Toyama Y, Nagura T. Comparison of knee mechanics among risky athletic motions for noncontact anterior cruciate ligament injury. J Appl Biomech. 2013;29(6):749-55.

55. Suzuki Y, Ae M, Takenaka S, Fujii N. Comparison of support leg kinetics between side-step and cross-step cutting techniques. Sports Biomech. 2014;13(2):144-53.

56. Franklyn-Miller A, Richter C, King E, Gore S, Moran K, Strike $\mathrm{S}$, et al. Athletic groin pain (part 2): a prospective cohort study on the biomechanical evaluation of change of direction identifies three clusters of movement patterns. Br J Sports Med. 2017;51(5):460-8.

57. Greig M. The influence of soccer-specific activity on the kinematics of an agility sprint. Eur J Sport Sci. 2009;9(1):23-33.

58. Jones P, Thomas C, Dos'Santos T, McMahon J, Graham-Smith $P$. The role of eccentric strength in $180^{\circ}$ turns in female soccer players. Sports. 2017;5(2):42.

59. Dos'Santos T, Thomas C, Jones AP, Comfort P. Mechanical determinants of faster change of direction speed performance in male athletes. J Strength Cond Res. 2017;31:696-705.

60. Graham-Smith P, Atkinson L, Barlow R, Jones P. Braking characteristics and load distribution in 180 degree turns. In: Proceedings of the 5th annual UK strength and conditioning association conference. Wyboston Lakes, United Kingdom; 2009.

61. Andrews JR, McLeod WD, Ward T, Howard K. The cutting mechanism. Am J Sports Med. 1977;5(3):111-21.

62. Jones P, Stones S, Smith L. A comparison of braking characteristics between pre-planned and unanticipated changing direction tasks in female soccer players: an exploratory study. Day 1. Posters-biomechanics, BASES annual conference, 25th November 2014, St Georges Park, Burton. J Sports Sci. 2014;32(sup 2):S25-6

63. Lee MJC, Lloyd DG, Lay BS, Bourke PD, Alderson JA. Effects of different visual stimuli on postures and knee moments during sidestepping. Med Sci Sports Exerc. 2013;45(9):1740-8.

64. Lee MJC, Lloyd DG, Lay BS, Bourke PD, Alderson JA. Different visual stimuli affect body reorientation strategies during sidestepping. Scand J Med Sci Sports. 2017;27(5):492-500. 
65. Young W, Farrow D. The importance of a sport-specific stimulus for training agility. Strength Cond J. 2013;35(2):39-43.

66. Rovan K, Kugovnik O, Holmberg LJ, Supej M. The steps needed to perform acceleration and turning at different approach speeds. Kinesiol Slov. 2014;20(1):38-50.

67. Yu B, Lin C-F, Garrett WE. Lower extremity biomechanics during the landing of a stop-jump task. Clin Biomech. 2006;21(3):297-305.

68. Markolf KL, Gorek JF, Kabo JM, Shapiro MS. Direct measurement of resultant forces in the anterior cruciate ligament. An in vitro study performed with a new experimental technique. J Bone Jt Surg Am. 1990;72(4):557-67.

69. Withrow TJ, Huston LJ, Wojtys EM, Ashton-Miller JA. The relationship between quadriceps muscle force, knee flexion, and anterior cruciate ligament strain in an in vitro simulated jump landing. Am J Sports Med. 2006;34(2):269-74.

70. Beynnon BD, Fleming BC, Johnson RJ, Nichols CE, Renström PA, Pope MH. Anterior cruciate ligament strain behavior during rehabilitation exercises in vivo. Am J Sports Med. 1995;23(1):24-34.

71. Beynnon B, Howe J, Pope MH, Johnson RJ, Fleming B. The measurement of anterior cruciate ligament strain in vivo. Int Orthop. 1992;16(1):1-12.

72. Markolf KL, O'Neill G, Jackson SR, McAllister DR. Effects of applied quadriceps and hamstrings muscle loads on forces in the anterior and posterior cruciate ligaments. Am J Sports Med. 2004;32(5):1144-9.

73. McLean SG, Huang X, Su A, Van Den Bogert AJ. Sagittal plane biomechanics cannot injure the ACL during sidestep cutting. Clin Biomech. 2004;19(8):828-38.

74. Shin CS, Chaudhari AM, Andriacchi TP. Valgus plus internal rotation moments increase anterior cruciate ligament strain more than either alone. Med Sci Sports Exerc. 2011;43(8):1484-91.

75. Markolf KL, Burchfield DM, Shapiro MM, Shepard MF, Finerman GAM, Slauterbeck JL. Combined knee loading states that generate high anterior cruciate ligament forces. J Orthop Res. 1995;13(6):930-5.

76. Kiapour AM, Demetropoulos CK, Kiapour A, Quatman CE, Wordeman SC, Goel VK, et al. Strain response of the anterior cruciate ligament to uniplanar and multiplanar loads during simulated landings: implications for injury mechanism. Am J Sports Med. 2016;44(8):2087-96.

77. Oh YK, Lipps DB, Ashton-Miller JA, Wojtys EM. What strains the anterior cruciate ligament during a pivot landing? Am J Sports Med. 2012;40(3):574-83.

78. Hewett TE, Myer GD, Ford KR, Heidt RS, Colosimo AJ, McLean SG, et al. Biomechanical measures of neuromuscular control and valgus loading of the knee predict anterior cruciate ligament injury risk in female athletes a prospective study. Am J Sports Med. 2005;33(4):492-501.

79. Grassi A, Smiley SP, Roberti di Sarsina T, Signorelli C, Marcheggiani Muccioli GM, Bondi A, et al. Mechanisms and situations of anterior cruciate ligament injuries in professional male soccer players: a YouTube-based video analysis. Eur J Orthop Surg Traumatol. 2017;27(7):697-981.

80. Inaba Y, Yoshioka S, Iida Y, Hay DC, Fukashiro S. A biomechanical study of side steps at different distances. J Appl Biomech. 2013;29(3):336-45.

81. Suchomel TJ, Nimphius S, Stone MH. The importance of muscular strength in athletic performance. Sports Med. 2016;46(10):1419-49.

82. Weinhandl JT, Earl-Boehm JE, Ebersole KT, Huddleston WE, Armstrong BS, O'connor KM. Reduced hamstring strength increases anterior cruciate ligament loading during anticipated sidestep cutting. Clin Biomech. 2014;29(7):752-9.
83. Nimphius S. Training change of direction and agility. In: Turner A, Comfort P, editors. Advanced strength and conditioning. Abdingdon, Oxon: Routledge; 2018. p. 291-308.

84. Padua DA, DiStefano LJ, Hewett TE, Garrett WE, Marshall SW, Golden GM, et al. National athletic trainers' association position statement: prevention of anterior cruciate ligament injury. J Athl Train. 2018;53:5-19.

85. Quatman CE, Quatman-Yates CC, Hewett TE. A 'Plane'explanation of anterior cruciate ligament injury mechanisms. Sports Med. 2010;40(9):729-46.

86. Sharir R, Rafeeuddin R, Staes F, Dingenen B, George K, Vanrenterghem $\mathrm{J}$, et al. Mapping current research trends on anterior cruciate ligament injury risk against the existing evidence: in vivo biomechanical risk factors. Clin Biomech. 2016;37:34-43.

87. Hewett TE. Preventive biomechanics: a paradigm shift with a translational approach to biomechanics. J Sci Med Sport. 2017;20:e67.

88. Pappas E, Shiyko MP, Ford KR, Myer GD, Hewett TE. Biomechanical deficit profiles associated with ACL injury risk in female athletes. Med Sci Sports Exerc. 2016;48(1):107-13.

89. Krosshaug T, Nakamae A, Boden BP, Engebretsen L, Smith G, Slauterbeck JR, et al. Mechanisms of anterior cruciate ligament injury in basketball video analysis of 39 cases. Am J Sports Med. 2007;35(3):359-67.

90. McLean SG, Huang X, van den Bogert AJ. Association between lower extremity posture at contact and peak knee valgus moment during sidestepping: implications for ACL injury. Clin Biomech. 2005;20(8):863-70.

91. Markolf KL, Burchfield DM, Shapiro MM, Shepard MF, Finerman GA, Slauterbeck JL. Combined knee loading states that generate high anterior cruciate ligament forces. J Orthop Res. 1995;13(6):930-5.

92. Shin CS, Chaudhari AM, Andriacchi TP. The effect of isolated valgus moments on ACL strain during single-leg landing: a simulation study. J Biomech. 2009;42(3):280-5.

93. Withrow TJ, Huston LJ, Wojtys EM, Ashton-Miller JA. The effect of an impulsive knee valgus moment on in vitro relative ACL strain during a simulated jump landing. Clin Biomech. 2006;21(9):977-83.

94. Hewett TE, Torg JS, Boden BP. Video analysis of trunk and knee motion during non-contact anterior cruciate ligament injury in female athletes: lateral trunk and knee abduction motion are combined components of the injury mechanism. Br J Sports Med. 2009;43(6):417-22.

95. Brown SR, Brughelli M, Hume PA. Knee mechanics during planned and unplanned sidestepping: a systematic review and meta-analysis. Sports Med. 2014;44(11):1573-88.

96. Almonroeder TG, Garcia E, Kurt M. The effects of anticipation on the mechanics of the knee during single leg cutting tasks: a systematic review. Int J Sports Phys Therapy. 2015;10(7):918.

97. Serpell BG, Young WB, Ford M. Are the perceptual and decision-making components of agility trainable? A preliminary investigation. J Strength Cond Res. 2011;25(5):1240-8.

98. Haff GG, Stone MH. Methods of developing power with special reference to football players. Strength Cond J. 2015;37(6):2-16.

99. Haff GG, Nimphius S. Training principles for power. Strength Cond J. 2012;34(6):2-12.

100. Keiner M, Sander A, Wirth K, Caruso O, Immesberger P, Zawieja M. Strength performance in youth: trainability of adolescents and children in the back and front squats. J Strength Cond Res. 2013;27(2):357-62.

101. Cormie P, McGuigan MR, Newton RU. Adaptations in athletic performance after ballistic power versus strength training. Med Sci Sports Exerc. 2010;42(8):1582-98. 
102. Rand MK, Ohtsuki T. EMG analysis of lower limb muscles in humans during quick change in running directions. Gait Posture. 2000;12(2):169-83.

103. Neptune RR, Wright IC, Van Den Bogert AJ. Muscle coordination and function during cutting movements. Med Sci Sports Exerc. 1999;31:294-302.

104. Cowling EJ, Steele JR. Is lower limb muscle synchrony during landing affected by gender? Implications for variations in ACL injury rates. J Electromyogr Kinesiol. 2001;11(4):263-8.

105. Spiteri T, Nimphius S, Hart NH, Specos C, Sheppard JM, Newton RU. The contribution of strength characteristics to change of direction and agility performance in female basketball athletes. $\mathbf{J}$ Strength Cond Res. 2014;28(9):2415-23.

106. Spiteri T, Newton RU, Binetti M, Hart NH, Sheppard JM, Nimphius S. Mechanical determinants of faster change of direction and agility performance in female basketball athletes. J Strength Cond Res. 2015;28(3):2205-14.

107. Watts D. A brief review on the role of maximal strength in change of direction speed. J Aust Strength Cond. 2015;23(2):100-8.

108. Suchomel TJ, Comfort P, Lake JP. Enhancing the force-velocity profile of athletes using weightlifting derivatives. Strength Cond J. 2017;39(1):10-20.

109. Jones P, Bampouras TM, Marrin K. An investigation into the physical determinants of change of direction speed. J Sports Med Phys Fitness. 2009;49(1):97-104.

110. de Hoyo M, Sañudo B, Carrasco L, Mateo-Cortes J, DomínguezCobo S, Fernandes O, et al. Effects of 10-week eccentric overload training on kinetic parameters during change of direction in football players. J Sports Sci. 2016;34(14):1380-7.

111. Green BS, Blake C, Caulfield BM. A comparison of cutting technique performance in rugby union players. J Strength Cond Res. 2011;25(10):2668-80.

112. Maloney SJ, Richards J, Nixon DG, Harvey LJ, Fletcher IM. Do stiffness and asymmetries predict change of direction performance? J Sports Sci. 2016;35(6):547-56.

113. Spiteri T, Hart NH, Nimphius S. Offensive and defensive agility: a sex comparison of lower body kinematics and ground reaction forces. J Appl Biomech. 2014;30(4):514-20.

114. Houck JR, Duncan A, Kenneth E. Comparison of frontal plane trunk kinematics and hip and knee moments during anticipated and unanticipated walking and side step cutting tasks. Gait Posture. 2006;24(3):314-22.

115. Davis RB, Ounpuu S, Tyburski D, Gage JR. A gait analysis data collection and reduction technique. Hum Mov Sci. 1991;10(5):575-87.

116. David S, Komnik I, Peters M, Funken J, Potthast W. Identification and risk estimation of movement strategies during cutting maneuvers. J Sci Med Sport. 2017;20(12):1075-80.

117. Suzuki Y, Ae M, Enomoto Y. A kinematic analysis of cutting motion with side-step and cross-step techniques. Jpn J Phys Educ Hlth Sport Sci. 2010;55:81-95.

118. Haff GG, Triplett NT. Essentials of strength training and conditioning. 4th ed. Champaign, Illinois: Human kinetics; 2015.

119. Young W, Farrow D. A review of agility: practical applications for strength and conditioning. Strength Cond J. 2006;28(5):24-9.

120. Jeffreys I, Moody J. Strength and conditioning for sports performance. Abingdon: Routledge; 2016.

121. Holding R, Meir R. Applying biomechanical research to coaching instruction of stepping movements in rugby football. Strength Cond J. 2014;36(3):8-12.

122. Park S-K, Stefanyshyn DJ, Ramage B, Hart DA, Ronsky JL. Alterations in knee joint laxity during the menstrual cycle in healthy women leads to increases in joint loads during selected athletic movements. Am J Sports Med. 2009;37(6):1169-77.
123. Sanna G, O'Connor KM. Fatigue-related changes in stance leg mechanics during sidestep cutting maneuvers. Clin Biomech. 2008;23(7):946-54.

124. O'Connor KM, Bottum MC. Differences in cutting knee mechanics based on principal components analysis. Med Sci Sports Exerc. 2009;41(4):867-78.

125. McLean SG, Lipfert SW, Van den Bogert AJ. Effect of gender and defensive opponent on the biomechanics of sidestep cutting. Med Sci Sports Exerc. 2004;36(6):1008-16.

126. Pollard CD, Davis IM, Hamill J. Influence of gender on hip and knee mechanics during a randomly cued cutting maneuver. Clin Biomech. 2004;19(10):1022-31.

127. Sigward SM, Powers CM. The influence of gender on knee kinematics, kinetics and muscle activation patterns during side-step cutting. Clin Biomech. 2006;21(1):41-8.

128. Patla AE, Adkin A, Ballard T. Online steering: coordination and control of body center of mass, head and body reorientation. Exp Brain Res. 1999;129(4):629-34.

129. Patla AE, Prentice SD, Robinson C, Neufeld J. Visual control of locomotion: strategies for changing direction and for going over obstacles. J Exp Psychol Hum Percept Perform. 1991;17(3):603-34.

130. Xu D, Carlton LG, Rosengren KS. Anticipatory postural adjustments for altering direction during walking. J Mot Behav. 2004;36(3):316-26.

131. Qiao M, Brown B, Jindrich DL. Compensations for increased rotational inertia during human cutting turns. J Exp Biol. 2014;217(3):432-43.

132. Wheeler KW, Sayers MGL. Modification of agility running technique in reaction to a defender in rugby union. J Sports Sci Med. 2010;9(3):445-51.

133. Mornieux G, Gehring D, Fürst P, Gollhofer A. Anticipatory postural adjustments during cutting manoeuvres in football and their consequences for knee injury risk. J Sports Sci. 2014;32(13):1255-62.

134. Yeow C, Lee P, Goh J. Sagittal knee joint kinematics and energetics in response to different landing heights and techniques. Knee. 2010;17(2):127-31.

135. Jones PA, Barber OR, Smith LC. Changing pivoting technique reduces knee valgus moments. J Sports Sci. 2015;33(1):S62.

136. Young WB, James R, Montgomery I. Is muscle power related to running speed with changes of direction? J Sports Med Phys Fitness. 2002;42(3):282-8.

137. Vanrenterghem J, Gormley D, Robinson M, Lees A. Solutions for representing the whole-body centre of mass in side cutting manoeuvres based on data that is typically available for lower limb kinematics. Gait Posture. 2010;31(4):517-21.

138. Rouissi M, Chtara M, Owen A, Chaalali A, Chaouachi A, Gabbett T, et al. Effect of leg dominance on change of direction ability amongst young elite soccer players. J Sports Sci. 2016;34(6):542-8.

139. Asadi A, Arazi H, Young WB, Saez DVE. The effects of plyometric training on change of direction ability: a meta analysis. Int J Sports Physiol Perform. 2016;11(5):563-73.

140. McCormick BT, Hannon JC, Newton M, Shultz B, Detling N, Young WB. The effects of frontal-and sagittal-plane plyometrics on change-of-direction speed and power in adolescent female basketball players. Int J Sports Physiol Perform. 2016;11(1):102-7.

141. Dello lacono A, Martone D, Milic M, Johnny P. Vertical- vs. horizontal-oriented drop-jump training: chronic effects on explosive performances of elite handball players. J Strength Cond Res. 2016;31(4):921-31.

142. Plisk SS. Speed, agility, and speed-endurance development. Essent Strength Train Cond. 2000:471-91. 
143. Marshall BM, Moran KA. Which drop jump technique is most effective at enhancing countermovement jump ability, Countermovement drop jump or bounce drop jump? J Sports Sci. 2013;31(12):1368-74.

144. Herrington L, Munro A, Comfort P. A preliminary study into the effect of jumping-landing training and strength training on frontal plane projection angle. Manual Therapy. 2015;20(5):680-5.

145. Herrington L. The effects of 4 weeks of jump training on landing knee valgus and crossover hop performance in female basketball players. J Strength Cond Res. 2010;24(12):3427-32.

146. Herrington LC, Comfort P. Training for prevention of ACL injury: incorporation of progressive landing skill challenges into a program. Strength Cond J. 2013;35(6):59-65.
147. Hewett TE, Stroupe AL, Nance TA, Noyes FR. Plyometric training in female athletes: decreased impact forces and increased hamstring torques. Am J Sports Med. 1996;24(6):765-73.

148. Schmidtbleicher D. Training for power events. Strength Power Sport. 1992;1:381-95.

149. Sinsurin K, Vachalathiti R, Jalayondeja W, Limroongreungrat W. Knee muscular control during jump landing in multidirections. Asian J Sports Med. 2016;7(2):e31248.

150. Pappas E, Nightingale EJ, Simic M, Ford KR, Hewett TE, Myer GD. Do exercises used in injury prevention programmes modify cutting task biomechanics? A systematic review with meta-analysis. Br J Sports Med. 2015;49(10):673-80. 